\section{HUMANASE SOCIAIS \\ V.9 • N.2 • 2021 • Fluxo Contínuo \\ ISSN Digital: 2316-3801 \\ ISSN Impresso: 2316-3348 \\ DOI: 10.17564/2316-3801.2021v9n2p455-467}
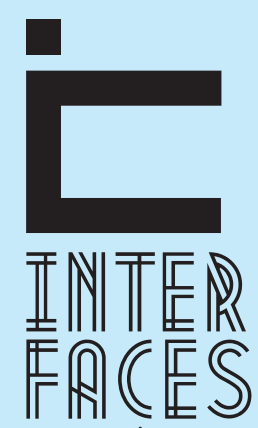

CIENTÍFICAS

\title{
REGIME INTERNACIONAL DE PROTEÇÃO AO PATRIMÔNIO CULTURAL IMATERIAL E MEIO AMBIENTE
}

INTERNATIONAL REGIME OF PROTECTION TO THE IMATERIAL CULTURAL HERITAGE AND ENVIROMENT

\section{RÉGIMEN INTERNACIONAL DE PROTECCIÓN DEL PATRIMONIO CULTURAL INMATERIAL Y DEL MEDIO AMBIENTE}

Alexandre Melo Diniz ${ }^{1}$ Dimas Pereira Duarte Júnior ${ }^{2}$

\section{RESUMO}

0 presente artigo, teve por objetivo analisar o processo de construção do regime jurídico internacional de proteção do patrimônio cultural imaterial. Para tanto, foi necessário explorar a gênese histórica internacional da proteção ao patrimônio cultural imaterial e apresentar sua correlação com a proteção dos direitos humanos e do meio ambiente. Trata-se de pesquisa bibliográfica e documental e a metodologia utilizada para análise foi qualitativa com o emprego de estudo bibliográfico especializado e pesquisa histórica. Adota-se, como referencial teórico, Boaventura de Sousa Santos, mais especificamente sua obra Ecologia dos Saberes. A questão que orienta a discussão é: qual a relação entre saberes tradicionais, meio ambiente e direitos humanos evidenciada no âmbito do regime internacional de proteção do patrimônio cultural imaterial? O trabalho, partiu da premissa que salvaguardar os saberes tradicionais é forma de reconhecer a sua importância, tendo em vista que integra não só uma face patrimônio cultural imaterial, mas também a dimensão humana da biodiversidade. A conclusão a que se chega é que, o saber tradicional foi tido, por muito tempo, apenas como folclore e que, pouco a pouco, impulsionado pelo movimento do socioambientalismo, a sua proteção jurídica internacional foi sendo construída no intuito de ampliar seu espectro de abrangência e contribuir para o seu reconhecimento como dimensão humana da biodiversidade e, portanto, como um direito humano e fundamental.

\section{PALAVRAS-CHAVE}

Meio Ambiente. Patrimônio Cultural Imaterial. Regime Internacional. Saber Tradicional. 


\section{ABSTRACT}

The present essay has as scope to analyze the construction process of the immaterial cultural heritage legal framework. For that purpose, it was necessary to explore the historical genesis of the immaterial cultural heritage and show the relation with the environment protection and the human rights. This article is about bibliography and documental Search and the methodology used for to analyze was qualitative with bibliographic study and historical survey. The theoretical framework is Boaventura de Sousa Santos, specifically your book "Ecologia dos Saberes". The premise of this essay is: what relation between traditional knowledge, environment and human rights evidenced in the international regime of protection of the immaterial cultural heritage? This work stars of the premise that to safeguard the immaterial cultural heritage is a way to recognize your importance, once it not composes only one face of the immaterial cultural heritage, but the human dimension of biodiversity. The conclusion is that the immaterial cultural heritage was visualized only as folklore for many years and that gradually, promoted by socioenvironmental, its international juridic protection was built to extend the range spectrum and contribute to the acknowledgment how human dimension of biodiversity and, therefore, as a human and fundamental right.

\section{KEYWORDS}

Environment. Immaterial Cultural Heritage. International Regime. Traditional knowledgement

\section{RESUMEN}

Este artículo tuvo como objetivo analizar el proceso de construcción del régimen jurídico internacional para la protección del patrimonio cultural inmaterial. Con este fin, era necesario explorar la génesis histórica internacional de la protección del patrimonio cultural inmaterial y presentar su correlación con la protección de los derechos humanos y el medio ambiente. Se trata de una investigación bibliográfica y documental y la metodología utilizada para el análisis fue cualitativa con el uso de estudios bibliográficos especializados e investigación histórica. Boaventura de Sousa Santos, más concretamente, se adopta como referencia teórica su obra Ecología del Conocimiento. La pregunta que guía el debate es: ¿cuál es la relación entre los conocimientos tradicionales, el medio ambiente y los derechos humanos que se evidencia en el marco del régimen internacional de protección del patrimonio cultural inmaterial? El trabajo, basado en la premisa de que la salvaguardia de los conocimientos tradicionales es una forma de reconocer su importancia, ya que integra no sólo una cara de patrimonio cultural inmaterial, pero también la dimensión humana de la biodiversidad. La conclusión a la que se ha llegado es que los conocimientos tradicionales se han tenido durante mucho tiempo 
sólo como folclore y que, poco a poco, impulsados por el movimiento del socioambientalismo, su protección jurídica internacional se fue construyendo con el fin de ampliar su espectro de cobertura y contribuir a su reconocimiento como una dimensión humana de la diversidad biológica y, por lo tanto, como un derecho humano fundamental.

\section{PALABRAS CLAVE}

Medio ambiente. Patrimonio Cultural Inmaterial. Régimen Internacional. Saber tradicional.

\section{INTRODUCÇÃO}

Tradicionalmente, o conceito de biodiversidade tem sido entendido, prioritariamente, a partir de suas dimensões ecológicas, restando, o próprio conceito de meio ambiente, muitas vezes, restrito à sua dimensão natural. Contudo, o conceito de meio ambiente transcende a visão ecológica e, cada vez mais, deve incluir, também, a dimensão social, que desvela muitas nuances da relação do homem com a natureza. Dessa forma, o presente artigo, aborda a biodiversidade em sua dimensão social por meio da gênese histórica dos instrumentos normativos internacionais de proteção ao patrimônio cultural imaterial e sua interdependência com o direito ambiental, sendo os dois ramos fundamentais para alcançar o desenvolvimento sustentável.

Nesta perspectiva, a interdependência entre meio ambiente e patrimônio cultural imaterial é sustentada a partir da gênese histórica do direito internacional e por meio da análise dos instrumentos internacionais com finalidade de evidenciar que ambos são formas de proteção dos direitos humanos. Sob o mesmo ponto de vista, o presente artigo aborda o patrimônio cultural imaterial como dimensão da biodiversidade, sendo sustentada a visão de biodiversidade como sociobiodiversidade e ambientalismo como socioambientalismo.

O texto propõe uma reflexão histórica e crítica sobre o processo de construção do regime internacional de proteção do patrimônio cultural imaterial e a questão que se pretende enfrentar é: qual a relação existente entre patrimônio cultural imaterial, meio ambiente e direitos humanos no contexto da afirmação e reconhecimento do patrimônio cultural imaterial como dimensão humana da biodiversidade?

Para responder à pergunta é necessário a análise da legislação de proteção ao patrimônio cultural e do meio ambiente, buscando demonstrar que a proteção inicial era realizada apenas em prol do patrimônio cultural material. Além disso, é evidenciada a interdependência do meio ambiente com a cultura por meio da tutela internacional do meio ambiente de forma sistêmica pela Organização das Nações Unidas para a Educação, a Ciência e a Cultura (UNESCO).

Em seguida, é demonstrada a luta pelo reconhecimento do patrimônio cultural imaterial e as discussões ocorridas ao longo do século XX. Por fim, é possível constatar que o principal instrumento normativo em âmbito internacional de proteção ao patrimônio cultural imaterial foi elaborado somente no século XXI, no ano de 2003 na $32^{\text {a }}$ reunião da UNESCO realizada em Paris. 
O presente estudo, tem como referencial teórico Boaventura de Sousa Santos, uma vez que partimos do pressuposto que salvaguardar o patrimônio cultural e reconhecê-lo como parte integrante da biodiversidade é medida que prestigia a ecologia dos saberes, isto é, a busca pela igualdade entre os diferentes tipos de conhecimentos e a potencialização de suas contribuições para toda sociedade.

Nesse sentido, partimos da premissa que todas as culturas são incompletas e que a linha abissal entre ciência e culturas tradicionais, representadas aqui pelo patrimônio cultural imaterial, deve ser superada com objetivo de promover o desenvolvimento sustentável a partir de outras perspectivas.

Em se tratando da gênese histórica da proteção ao patrimônio cultural imaterial serão utilizados instrumentos normativos internacionais: Resolução sobre a Conservação de Monumentos Históricos e de Obras de Arte; Convenção Internacional sobre Direitos do Autor; Convenção Relativa à Proteção do Patrimônio Mundial, Cultural e Natural; Recomendação da UNESCO sobre a Salvaguarda da Cultura Tradicional e Popular e Convenção para Salvaguarda do Patrimônio Cultural Imaterial.

\section{ANÁLISE DA GÊNESE HISTÓRICA DA PROTEÇÃO INTERNACIONAL DO PATRIMÔNIO CULTURAL E MEIO AMBIENTE}

A proteção do patrimônio cultural durante séculos foi voltada apenas para o patrimônio cultural material e, mais especificamente, para monumentos históricos, sendo noticiado o surgimento destes, no século XV, por volta do ano de 1420 (CUREAU, 2015).

Muito se debate sobre o conceito moderno de proteção do patrimônio cultural como é visto nos dias de hoje. Pesquisadores, afirmam que o conceito surge durante a Revolução Francesa, no século XVIII, tendo em vista que houve a premência de inventariar os bens confiscados da nobreza e do clero (CUREAU, 2015).

A Revolução Francesa foi responsável por incêndios em igrejas, destruição de obras de arte em museus e patrimônios que tivessem qualquer ligação com as memórias de um passado corrupto e tirano, assim surge a necessidade de proteção ao patrimônio. 0 termo "patrimônio" era visto com ambiguidade no século XVIII, sendo substituído pelo termo "monumento" (CUREAU, 2015).

A partir dos anos 1900, inicia-se a distinção de "monumento" e "monumento histórico". 0 primeiro, passou a ter o significado de patrimônio cultural universal, com função de preservar a memória e identidade coletivas; já o monumento histórico, era visto como um objeto da elite, uma vez que apenas as elites entendiam seu significado por possuírem o conhecimento de sua história e da cultura ocidental (CABRAL, 2011).

Os monumentos históricos tiveram relevante função na construção da proteção ao patrimônio cultural em âmbito internacional, tendo em vista que foi por meio da Carta de Atenas, oriunda da Conferência Internacional sobre a Restauração dos Monumentos, ocorrida em 1931, que se iniciou a proteção ao patrimônio cultural. A Conferência foi marcada pela participação seletiva de Europeus, sendo possível visualizar a origem eurocêntrica do conceito de patrimônio (CABRAL, 2011).

As conclusões de 1931, foram expostas na Resolução sobre a Conservação de Monumentos Históricos e de Obras de Arte, sendo reconhecida pela Assembleia da Sociedade das Nações. A referida 
resolução assim dispôs: “a conservação do património artístico e arqueológico da humanidade interessa à comunidade dos Estados depositários e defensores da civilização". Dessa forma, foi reconhecido, pela primeira vez, o patrimônio como interesse internacional, ultrapassando os limites dos Estados (CABRAL, 2011).

A Resolução sobre Conservação de Monumentos Históricos e de Obras de Arte foi a pioneira no processo de universalização do patrimônio, podendo ser citada a Ação Internacional de Proteção aos Monumentos ocorrida em Abu Simbel, no Egito, nos anos cinquenta (CABRAL, 2011).

Em 1945, foi criada a UNESCO com objetivo de "garantir a paz por meio da cooperação intelectual entre as nações, acompanhando o desenvolvimento mundial”. A UNESCO, com sua atuação em âmbito internacional, realizou grandes encontros internacionais sobre meio ambiente, demonstrando como meio ambiente e cultura são interdependentes.

A primeira Conferência que reuniu cientistas dos mais variados Estados foi a Conferência das Nações Unidas para a Conservação e Utilização dos Recursos naturais em 1949, essa, possuía o objetivo de investigar a situação ambiental global (ZANIRATO et al., 2007).

Similarmente a UNESCO, em 1962, aprovou a Recomendação relativa à salvaguarda da beleza e do caráter das paisagens e sítios, no intuito, de proteger as paisagens naturais por meio de planejamento urbano, criação de parques e reservas naturais.

Pode ser citada ainda, a Conferência Intergovernamental de Especialistas sobre Bases Cientificas para o Uso e Conservação Racionais dos Recursos da Biosfera, que se discutiu a problemática dos impactos ambientais ocasionados pela ação do homem.

Assim como a UNESCO, também tutelava o meio ambiente e realizou a primeira grande Conferência para tratar de proteção ambiental em 1972, em Estocolmo, intitulada como Conferência sobre Meio Ambiente Humano. Foi definida, na Conferência, a necessidade de cada Estado assumir o compromisso de que as suas ações não seriam prejudiciais às áreas externas a sua jurisdição. Outra decisão tomada em Estocolmo, foi a criação do Programa das Nações Unidas para o Meio Ambiente (PNUMA), centralizando as atividades ambientais da Organização das Nações Unidas (ONU).

Ainda no ano de 1972, a UNESCO, organizou em Paris a Convenção Relativa à Proteção do Patrimônio Mundial, Cultural e Natural, sendo mais uma vez a noção de cultura e meio ambiente trabalhada de modo conjunto. Em Paris, foram tomadas diversas atitudes importantes, iniciando pela decisão que a proteção ambiental não poderia ser realizada somente em escala nacional.

Nesse sentido, em seu artigo $7^{\circ}$, a Convenção traz a ideia de proteção internacional do patrimônio ao optar por "um sistema de cooperação e assistência internacional destinado a secundar os Estados-partes, nos esforços que desenvolvam para preservar e identificar esse patrimônio" e criar o Comitê do Patrimônio Mundial (BRASIL, 1997).

A referida Convenção, também trouxe a ideia de Patrimônio da Humanidade, sendo englobados monumentos, edifícios e os lugares dotados de valor global notável, na ótica da história, da arte, da ciência, ou do ponto de vista estético, etnológico ou antropológico. Verifica-se que a proteção foi realizada somente quanto ao patrimônio cultural material.

Somente em 1982, a UNESCO, adotou o conceito abrangente de cultura, passando a definir cultura como 
[...] conjunto dos traços distintivos, espirituais e materiais, intelectuais e afetivos, que caracterizam uma sociedade ou um grupo social, englobando, além das artes e das letras, os modos de vida, os direitos fundamentais do ser humano, os sistemas de valores, as tradições e as crenças. (CUREAU, 2015, p. 125).

Dessa forma, ao adotar o conceito abrangente de cultura, a UNESCO, reconhece a existência de culturas intangíveis. Ademais, podemos observar pela atuação da UNESCO, por seus instrumentos internacionais produzidos, que a dimensão natural e cultural, deve ser visualizada com uma visão de complementação mútua com objetivo de alcançar o desenvolvimento sustentável.

\section{RECONHECIMENTO DO PATRIMÔNIO CULTURAL IMATERIAL E A CONCRETIZAÇÃO DO INSTRUMENTO NORMATIVO INTERNACIONAL PARA SUA PROTEÇÃO}

A proteção ao patrimônio cultural, iniciou-se com a salvaguarda dos patrimônios materiais, ou seja, os patrimônios tangíveis, sendo que o próprio conceito de cultura somente passou a abarcar o patrimônio cultural imaterial em 1982.

Entretanto, as ideias sobre a existência do patrimônio cultural imaterial e sua necessidade de proteção são anteriores a própria UNESCO, com início das discussões, em âmbito internacional, na Comissão Internacional de Cooperação Intelectual criada em 1922 pela Sociedade das Nações. Ainda nos anos 1920, mais especificamente, no ano de 1928, surge a Comissão Internacional das Artes Populares que era responsável pela cooperação internacional na área da arte, dos museus e da cultura. Esta, auxiliou a UNESCO até 1964, ano em que decidiu desassociar das Nações Unidas e adotar a designação de Sociedade Internacional de Etnologia com atuação principalmente na Europa (CUREAU, 2015).

A partir de então foi travada uma verdadeira luta para o reconhecimento do patrimônio cultural imaterial, a problemática envolvia grandes organismos multilaterais como a UNESCO, o Programa das Nações Unidas para o Meio Ambiente (PNUMA), a Organização Mundial de Propriedade Intelectual (OMPI) e a Organização Mundial do Comércio (OMC).

A problemática envolveu a complexa definição de patrimônio cultural imaterial e qual setor seria responsável por sua proteção. Por muitos anos o conceito de patrimônio cultural imaterial era visto como folclore e as discussões giravam em torno de se o mesmo, poderia ser regulamentado no âmbito do direito autoral (ZANIRATO, et al., 2007).

A UNESCO, desempenhou função fundamental no processo de salvaguarda do patrimônio cultural imaterial, tendo em vista que realizou múltiplas convenções internacionais. Ela foi responsável pela realização da Convenção Internacional sobre Direitos do Autor em 1952, na cidade de Genebra; o principal objetivo da reunião foi a necessidade de regulamentar a proteção do direito de autor sobre obras científicas, literárias e artísticas. A partir dos debates, com relação os direitos dos autores, inicia-se as discussões sobre como resguardar o direito de obras onde a identidade do autor não era conhecida, como por exemplo as advindas das tradições populares (BO, 2003). 
Em Estocolmo, no ano de 1967, foram retomadas as discussões sobre direito do autor e debates sobre a relação de folclore e copyright, visando salvaguardar as manifestações culturais, nos moldes do direito autoral. A discussão ainda se centrava na dificuldade de criar mecanismos de salvaguarda de obras onde a identidade do autor não era conhecida (BO, 2003).

Ainda no ano de 1967, foi criada a OMPI, sendo instituída em 1970 na esfera da ONU. A competência sobre a propriedade intelectual do conhecimento tradicional transpassou para a OMPI em tentativa de salvaguardar o patrimônio cultural imaterial em âmbito do direito de propriedade intelectual (ZANIRATO, et al., 2007).

A UNESCO continuou se esforçando e nos anos de 1970 buscou os órgãos da OMPI e o Comitê Executivo da Convenção de Berna com a tentativa de definir a proteção internacional dos conhecimentos populares como direito autoral. Após debates não houve consenso na inclusão do conhecimento tradicional como direito de propriedade intelectual (BO, 2003).

Existiam alegações contra a aplicação dos direitos autorais em relação aos conhecimentos tradicionais, considerando que os direitos da propriedade não poderiam ser aplicados as obras sem autoria definida, tendo em vista que sem definir a titularidade não poderia ser realizada a exploração econômica e à cobrança de direitos. Dessa maneira, existia a impossibilidade de proteger o direito da propriedade quando esse direito é coletivo, ou seja, quando o direito é um patrimônio cultural imaterial (BO, 2003).

Com a impossibilidade de ter o patrimônio cultural intangível protegido por meio da Convenção Universal sobre os Direitos do Autor, alguns Países, como a Bolívia, atuaram fortemente junto à UNESCO para criação de um documento de proteção às artes populares e ao patrimônio cultural dos povos; havia a solicitação que a proteção realizada por meio da Convenção Universal sobre os Direitos do Autor, fosse expandida para o patrimônio cultural dos povos (BO, 2003).

A UNESCO recebeu a solicitação e iniciou a elaboração do documento intitulado como "possibilidades de criar um instrumento internacional para a proteção do folclore”. Após o estudo, a mesma, recusou os argumentos em razão da "falta de devidas fontes para a identificação das expressões do folclore que se queria proteger, falta de mecanismos eficazes para a proteção das expressões que se encontram em vários países e que têm várias origens" (ZANIRATO et al., 2007).

Em 1980, na 21 a Conferência Geral da UNESCO, foi solicitado estudos com a finalidade de criar uma norma internacional que salvaguardasse o folclore. A UNESCO em conjunto com a OMPI, elaborou em 1982, o documento intitulado como "Provisões Modelo de Leis Nacionais sobre a Proteção das Expressões do Folclore ante Ações Ilícitas e Prejudiciais”. Todavia, o documento acabou por ser rejeitado.

A UNESCO, visando tutelar o patrimônio cultural imaterial, persistiu tentando definir o conceito de folclore, chegando a fundar o Comitê de especialista sobre a Salvaguarda do Folclore e uma Seção para o patrimônio não material. Após longos debates entre os especialistas, foi criada a recomendação da UNESCO sobre a Salvaguarda da Cultura Tradicional e Popular.

Após as discussões, na década de 1980, ficou estabelecido que a proteção ao folclore não poderia ser realizada nos moldes do Direito do Autor, copyright, tendo em vista que o folclore é de propriedade coletiva, ou seja, seu domínio é público e "estava fora do contexto comercial, objeto da Universal Copyright Convention"(BO, 2003, p. 82). 
A UNESCO, superando a discussão sobre a tutela pela propriedade intelectual, desenvolveu a Recomendação sobre a Salvaguarda da Cultura Tradicional e Popular que teve origem na Conferência Geral da UNESCO realizada em Paris no ano de 1989. O objetivo era recomendar aos Estados-Membros que realizassem medidas legais para salvaguardar o folclore. Além disso, foram sugeridas políticas culturais como: criação de inventários das manifestações folclóricas, criação de arquivos e museus para o patrimônio intangível, divulgação dos saberes tradicionais.

Na década de noventa, mais especificamente no ano de 1992, surge a Convenção sobre a Diversidade Biológica, importante marco de proteção a diversidade biológica sendo seu objetivo "a utilização sustentável de seus componentes e a repartição justa e equitativa dos benefícios derivados da utilização dos recursos genéticos" (BRASIL, 1998, p.2).

A Convenção sobre Diversidade Biológica tem como foco a proteção dos recursos genéticos. Sabe-se que muitas substâncias extraídas das florestas tropicais foram utilizadas sem autorização por parte das comunidades tradicionais que detinham os direitos. A indústria farmacêutica explorou economicamente os recursos e as populações tradicionais não conseguiam ter o retorno esperado (SANTILLI, 2005).

A Convenção sobre Diversidade Biológica foi um passo importante para proteger o conhecimento tradicional associado ao patrimônio genético. Todavia, não resolveu a problemática da proteção dos saberes, das formas de expressão, celebrações, festas, danças populares, músicas e costumes, isto é, do patrimônio cultural imaterial.

Em mais uma tentativa de criar um instrumento normativo em âmbito internacional, para proteção do patrimônio cultural imaterial, a UNESCO trabalhando em conjunto com a OMPI, no final dos 1990, organizaram o Fórum Mundial sobre a Proteção do Folclore". A conservação do termo folclore foi mantida, tendo em vista que a OMPI entendia o patrimônio cultural imaterial como folclore.

Em 1999, na Conferência Internacional de Washington, a UNESCO continuou a buscar a devida proteção ao patrimônio cultural imaterial, destacando que as populações tradicionais detinham conhecimentos e valores que tornavam a produção de produtos em objetos, ou seja, o saber fazer deveria ser tão protegido quanto a própria materialização do patrimônio (ZANIRATO et al., 2007).

\section{SÉCULO XXI: MARCO DA SALVAGUARDA DO PATRIMÔNIO CULTURAL IMATERIAL}

A gênese histórica da proteção ao patrimônio cultural imaterial demonstra que existiu muitos debates e grande interesse por parte da UNESCO com objetivo de normatizar em plano internacional a proteção do patrimônio intangível. A UNESCO, deixou claro a importância dos aspectos culturais e do modo de expressão na dimensão simbólica, podendo citar: os ritos, cerimônias, instrumentos de comunicação, valores e crenças.

A proteção ao patrimônio cultural imaterial é a forma de reconhecermos que outras culturas são tão importantes quanto o conhecimento científico. Nesta perspectiva, partimos da premissa que é necessário reconhecer as culturas como incompletas e aprender sempre com outras culturas com objetivo de realizar a ecologia dos saberes. 0 reconhecimento da diversidade cultural é um modo de prestigiar 
a ecologia dos saberes, uma vez que reconhecer saberes não científicos, aprender com eles e garantir participação dos diversos grupos sociais existentes é verdadeira forma de visão contra hegemônica.

Por meio do reconhecimento que é necessário salvaguardar a diversidade cultural, a UNESCO, produziu em 2001 a Declaração Universal sobre a Diversidade Cultural que, em seu artigo 4a , deixa claro a importância da diversidade cultural e da ligação com os direitos humanos.

Diversidade cultural é um imperativo ético, inseparável do respeito pela dignidade da pessoa humana. Implica o compromisso de respeitar os direitos humanos e as liberdades fundamentais, em particular os direitos das pessoas que pertencem a minorias e os dos povos autóctones. (BRASIL, 2006, on-line).

Os Estados membros se comprometeram e realizaram um plano de ação para a aplicação da Declaração Universal da UNESCO sobre a Diversidade Cultural. Em seu decimo quarto objetivo ficou definido que os Estados deveriam:

Respeitar e proteger os sistemas de conhecimento tradicionais, especialmente os das populações autóctones; reconhecer a contribuição dos conhecimentos tradicionais para a proteção ambiental e a gestão dos recursos naturais e favorecer as sinergias entre a ciência moderna e os conhecimentos locais. (BRASIL, 2006, on-line).

Foram, então, definidas, duas premissas de suma importância, a primeira é a proteção do conhecimento tradicional por parte dos Estados membros; a segunda, é a contribuição dos conhecimentos tradicionais para a proteção ambiental, demonstrando que por meio da cultura, representada aqui pelos conhecimentos tradicionais, podemos buscar o desenvolvimento sustentável.

A Declaração Universal sobre a Diversidade Cultural de 2001 e a Convenção da Diversidade Biológica de 1992, têm visões sobre a proteção aos conhecimentos tradicionais como forma de proteção ao meio ambiente. As duas normativas são exemplos da sociobiodiversidade e do socioambientalismo.

A visão de sociobiodiversidade é fundamental para compreendermos a necessidade de salvaguardar o patrimônio cultural imaterial, nesse sentido, a Declaração Universal sobre a Diversidade Cultural e a Convenção da Diversidade Biológica foram de suma importância.

Contudo, o marco histórico de proteção ao patrimônio cultural intangível é a Convenção para a Salvaguarda do Patrimônio Cultural imaterial que surge no século XXI, como o instrumento normativo em âmbito internacional, definindo o patrimônio cultural imaterial como parte integrante do patrimônio cultural.

Em sua $32^{a}$ reunião, realizada em Paris no ano de 2003, a UNESCO elaborou a Convenção para a Salvaguarda do Patrimônio Cultural Imaterial. No instrumento normativo ficou definido o conceito de patrimônio cultural imaterial em âmbito internacional:

Entende-se por "patrimônio cultural imaterial" as práticas, representações, expressões, conhecimentos e técnicas - junto com os instrumentos, objetos, artefatos e lugares culturais que lhes são associados - que as comunidades, os grupos e, em alguns casos, os indivíduos reconhecem como parte integrante de seu patrimônio cultural. Este patri- 
mônio cultural imaterial, que se transmite de geração em geração, é constantemente recriado pelas comunidades e grupos em função de seu ambiente, de sua interação com a natureza e de sua história, gerando um sentimento de identidade e continuidade e contribuindo assim para promover o respeito à diversidade cultural e à criatividade humana. (BRASIL, 2006, on-line).

Nessa perspectiva, o patrimônio cultural é composto tanto por patrimônios materiais que são tangíveis, quanto por patrimônios imateriais que são intangíveis. A proteção jurídica é justificada na medida em que o conjunto de manifestações além de constituírem identidades culturais são alternativas para buscarmos o desenvolvimento sustentável.

Assim, por meio da gênese histórica, foi possível visualizar que até chegarmos na Convenção de Salvaguarda do Patrimônio Cultural Imaterial foram necessárias várias discussões em âmbito internacional, sendo que a Convenção é de 2003 e ratificada pelo Brasil apenas em 2006. A referida Convenção é marco histórico de uma conquista, uma vez que foram necessários muitos debates e longos anos até sua criação.

\section{CONSIDERAÇÕES FINAIS}

Conforme exposto, o meio ambiente não se restringe a sua dimensão ecológica, sendo necessário visualizarmos a dimensão social da biodiversidade como integrante do meio ambiente. Nesta perspectiva, em âmbito internacional, a UNESCO realizou múltiplas convenções sobre meio ambiente em sua dimensão ecológica e em sua dimensão social. Ademais, buscou juntamente com outras organizações internacionais a confecção de instrumentos para proteção do patrimônio cultural em sua dimensão material e em sua dimensão imaterial, de modo ampliar a concepção de saber tradicional para além das práticas folclóricas.

Como visto, tradicionalmente, a proteção jurídica do patrimônio cultural, ao longo do século XX, se ocupou de enfrentar e regular o tema exclusivamente sob a perspectiva da sua dimensão material. Foi necessário um século de debates para surgir em âmbito internacional a Convenção para Salvaguarda do Patrimônio Cultura Imaterial, que se materializa somente no início do século XXI, quando no ano de 2006 a UNESCO aprova, em Paris, o texto que daria estabeleceria os contornos para a construção de um regime internacional de proteção do patrimônio cultural imaterial.

Em um primeiro momento, o grande lapso temporal, pode ser explicado pelas grandes discussões políticas e posições diferentes das organizações internacionais sobre a proteção ao patrimônio cultural imaterial que persistiram por todo século XX. Contudo, em um olhar mais atento, pode-se visualizar que o patrimônio cultural imaterial era entendido como folclore por organizações internacionais como a OMPI, deixando claro que existia uma linha abissal entre os saberes tradicionais e o conhecimento científico. Atualmente, essa linha é visualizada pela grande disparidade entre os saberes tradicionais e o conhecimento científico. 
Assim, os motivos que ocasionaram o grande lapso temporal para produção em âmbito internacional do instrumento de salvaguarda, podem ser visualizados atualmente, tendo em vista que a linha abissal entre conhecimento científico e os saberes tradicionais ainda existe. Todavia, é necessário mudarmos a mentalidade para buscar o desenvolvimento sustentável, uma vez que podemos aprender com os saberes tradicionais formas sustentáveis de vida.

Salvaguardar os saberes tradicionais é uma forma de reconhecer a sua importância como parte integrante do que se denomina de patrimônio cultural imaterial e de dimensão humana da biodiversidade. 0 saber tradicional enquanto considerado como forma de expressão do folclore não conseguiu ultrapassar a barreira das práticas colonialistas dos países do norte sobre os países do sul.

Impulsionado pelo movimento do socioambientalismo, a construção do regime internacional de proteção do patrimônio cultural imaterial e, por conseguinte, do regime que reconhece

o saber tradicional como uma face da biodiversidade, também irá exercer forte influência para ampliar sua proteção jurídica em âmbito internacional, que passa a reconhecê-lo como um autêntico direito humano e fundamental, exigível e oponível e até mesmo perante as Cortes Internacionais de proteção dos direitos humanos.

\section{REFERÊNCIAS}

BERTOLDI, Márcia Rodrigues. Saberes tradicionais como patrimônio cultural imaterial dinamizador do desenvolvimento sustentável. Revista novos estudos jurídicos, v. 19, n. 2, maio/ago. 2014.

BO, Lanari Batista João. 2003. Proteção do Patrimônio na UNESCO: ações e significados. Brasília: UNESCO, 2003.

BRASIL. Lei n ${ }^{13.123 / 2015 . ~ R e g u l a m e n t a ~ o ~ i n c i s o ~ I I ~ d o ~} \S 1^{\circ}$ e o $\S 4^{\circ}$ do art. 225 da Constituição Federal, o Artigo 1, a alínea j do Artigo 8, a alínea c do Artigo 10, o Artigo 15 e os $\S \S 3^{\circ}$ e $4^{\circ}$ do Artigo 16 da Convenção sobre Diversidade Biológica, promulgada pelo Decreto n² 2.519, de 16 de março de 1998; dispõe sobre o acesso ao patrimônio genético, sobre a proteção e o acesso ao conhecimento tradicional associado e sobre a repartição de benefícios para conservação e uso sustentável da biodiversidade; revoga a Medida Provisória n².186-16, de 23 de agosto de 2001; e dá outras providências. Disponível em: http://www.planalto.gov.br/ccivil_03/_Ato2015-2018/2015/Lei/ L13123.htm. Acesso em: 26 maio 2020.

BRASIL. Câmara dos Deputados. Decreto Legislativo nº 22, de 2006. Aprova o texto da Convenção para a Salvaguarda do Patrimônio Cultural Imaterial, celebrada em Paris, em 17 de outubro de 2003. Disponível em: https://www2.camara.leg.br/legin/fed/decleg/2006/decretolegislativo-22-1fevereiro-2006-540768-publicacaooriginal-41714-pl.html. Acesso em: 26 maio 2020. 
BRASIL, Decreto $\mathbf{n}^{0} \mathbf{2 . 5 1 9}$, de 16 de março de 1998. Promulga a Convenção sobre Diversidade Biológica, assinada no Rio de Janeiro, em 05 de junho de 1992. Disponível em: http://www.planalto. gov.br/ccivil_03/decreto/d2519.htm. Acesso em: 25 maio 2020.

BRASIL. Câmara dos Deputados. Decreto Legislativo n 74, de 1977. Aprova o texto da Convenção Relativa à Proteção do Patrimônio Mundial, Cultural e Natural. Disponível em: https://www2. camara.leg.br/legin/fed/decleg/1970-1979/decretolegislativo-74-30-junho-1977-364249publicacaooriginal-1-pl.html. Acesso em: 10 maio 2020.

CABRAL, Clara Bertrand. Património cultural imaterial: convenção da UNESCO e seus contextos. Lisboa, Portugal: EDIÇÕES 70, Lda, 2011.

CUREAU, Sandra. Dimensões das práticas culturais e direitos humanos. In: SOARES, Inês Virginia Prado; CUREAU, Sandra (org.). Bens culturais e direitos humanos. São Paulo: Edições Sesc São Paulo, 2015. pp. 113-135.

DANTAS, Fernando Antonio de Carvalho Dantas. Base jurídica para a proteção dos conhecimentos tradicionais. Revista CPC, São Paulo v. 1, n. 2, maio/out. 2006. pp. 80-95.

LEUZINGER, Márcia Dieguez; CUREAU, Sandra. 2008. Direito ambiental. Rio de Janeiro: Elsevier, 2008.

PELEGRINI, Sandra C. A. A gestão do patrimônio imaterial brasileiro na contemporaneidade. Revista História, Franca, São Paulo, v. 27, n. 2, 2008. pp. 145-173.

SANTILLI, Juliana. Socioambientalismo e novos direitos. São Paulo: Fundação Peirópolis, 2005.

SANTOS, Boaventura de Sousa. Para além do pensamento abissal: das linhas globais a uma ecologia de saberes. Construindo as Epistemologias do Sul: Antologia Esencial. Volume I: Para um pensamento alternativo de alternativas. Buenos Aires: CLACSO, 2018.

ZANIRATO, Silvia Helena; RIBEIRO, Wagner Costa. Conhecimento tradicional e propriedade intelectual nas organizações multilaterais. Revista Ambiente \& Sociedade, Campinas, v. 10, n. 1, jan./jun. 2007. pp. 39-55 
1 Mestre em Direitos Humanos pela Universidade Tiradentes - UNIT/SE; Graduado em Direito pelo Centro Universitário de Brasília - UniCEUB; Foi Auditor da Universidade de Brasília e Colaborador da Defensoria Pública do Distrito Federal junto ao Superior Tribunal de Justiça e Supremo Tribunal Federal; Auditor do Instituto Federal de Sergipe IFS. E-mail: alex.mdiniz@gmail.com

2 Doutor em Ciências Sociais: Relações Internacionais pela Pontifícia Universidade Católica de São Paulo - PUC-SP (2008); Mestre em Filosofia Política pela Universidade Federal de Goiás (2001); Graduado em Direito pela Universidade Católica de Goiás (1996); Professor e Pesquisador do Programa de Pós-graduação em Direitos (ME/DO) da Universidade Tiradentes - UNIT/SE.

E-mail: dimas.duartejr@gmail.com

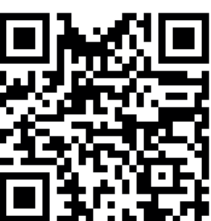

A autenticidade desse artigo pode ser conferida no site https://periodicos. set.edu.br



Este artigo é licenciado na modalidade acesso abertosob a Atribuição-Compartilhalgual CC BY-SA



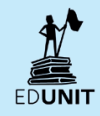

